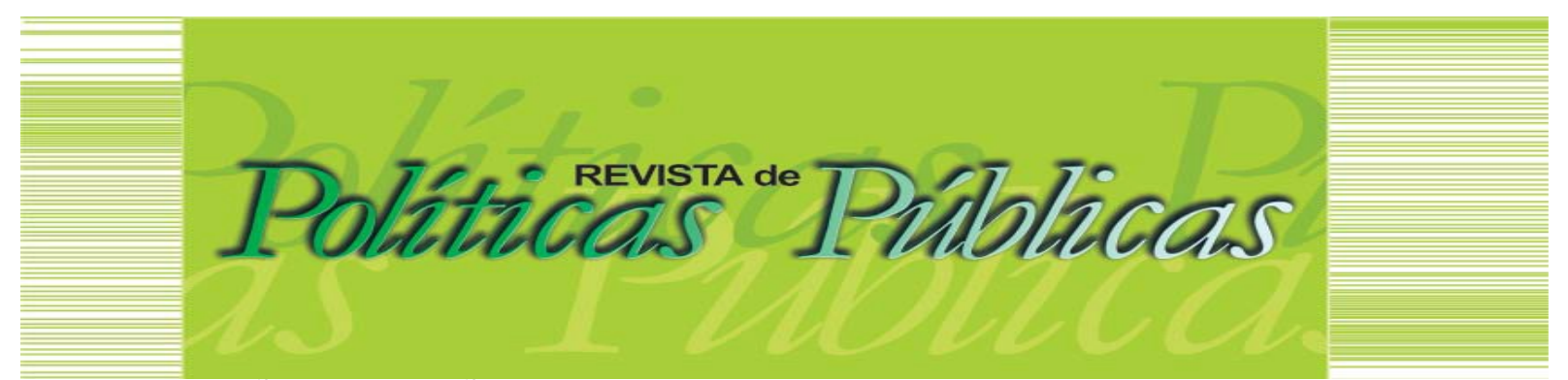

\title{
PRIVATIZAÇÃO DE FUNÇÕES SOCIAIS DO ESTADO BRASILEIRO: estudo a partir da política pública de saúde
}

\author{
Liliam dos Reis Souza Santos ${ }^{1}$
}

\section{Resumo}

O artigo aborda a privatização das funções sociais do Estado brasileiro a partir da terceirização da gestão de serviços públicos de saúde. Faz um debate teórico sobre o Estado e sua relação de unidade dialética orgânica ao capitalismo; mostra as bases legais dessas modalidades de gestão e da contrarreforma da saúde no Brasil; traz dados sobre a prevalência dessas entidades no Brasil e dos elementos que evidenciam a privatização. Assevera que esse processo solapa as pretensões públicas do Estado e mostranovo meio de apropriação da riqueza coletiva pelo capital.

Palavras-chave:Estado. Privatização. Política de saúde.

\section{PRIVATIZATION OF SOCIAL FUNCTIONS OF THE BRAZILIAN STATE: a study based on public health policy}

\begin{abstract}
It addresses the privatization of the Brazilian State's social functions through the outsourcing of the management of public health services. It makes a theoretical debate about the State and its relation of the organic dialectical unity with the capitalism; presents the legal bases of these modalities of health management and counter-reform in Brazil; brings data on the prevalence of these entities in Brazil and the numbers that show privatizations. It states that this process submits the public intentions of the State and shows a new way of appropriating collective wealth by capital.

Keywords: State. Privatization. Healthpolicy.
\end{abstract}

Artigo recebido em: 05/07/2021 Aprovado em: 20/11/2021 DOI: http://dx.doi.org/10.18764/2178-2865.v25n2p 950-964

\footnotetext{
${ }_{1}$ Assistente Social. Doutora em Política Social pelo Programa de Pós-Graduação em Política Social da Universidade de Brasília. Mestre em Serviço Social pelo Programa de Pós-Graduação em Serviço Social da Universidade Federal do Pará. Professora Adjunta do Departamento de Serviço Social da Universidade de Brasília. Assistente Social pela Universidade Federal do Pará. E-mail: liliamsouza@gmail.com
} 


\section{INTRODUÇÃO}

Este artigo tem por objeto de reflexão a expressiva e crescente tendência de concepções e práticas mercantis nas políticas sociais, particularmente na política pública de saúde, por meio da terceirização da gestão de hospitais e outras instituições de saúde vinculadas ao Sistema Único de Saúde - SUS. Nesse processo, embora políticas e serviços sociais permaneçam identificados como públicos, por envolverem o Estado, eles são ofertados e administrados por agentes privados, que os exploram lucrativamente, embora muitas organizações executoras se autointitulem "sem fins lucrativos".

Assevera-se, com base nos postulados teórico-metodológicos da tradição marxista, que tal dinâmica expressa a privatização das funções sociais do Estado capitalista -funções que incluem um rol de ações que incidem sobre a reprodução societária e as relações sociais vigentes, entre elas, a política social. Já que esses eventos evidenciam uma dupla tarefa do referido Estado: de legitimação da ordem burguesa, mediante oferta de políticas sociais, dentre outros mecanismos de coesão social; e de criação de condições para a acumulação de riqueza para setores mercantis.

Essa dinâmica corrobora uma forte imbricação das dimensões econômicas, sociais e políticas no sistema capitalista. Deste modo, a explicação dessa engenharia privatista é feita por meio de um debate teórico sobre o Estado capitalista, propugnando a existência de relação orgânica entre Estado e capitalismo, com base em duas mediações: a presença do Estado nas relações de produção e reprodução do capital e a interação estatal com as classes sociais fundamentais desse sistema. Com base nessa interpretação, o texto aborda os processos e tendências de privatização das funções sociais como uma agenda mundial e situa esse processo no Brasil.

Aqui, são apresentados as particularidades de proteção social, os marcos legais dessa estratégia privatistae dados recentes obtidos por meio do IBGE, sites jornalísticos, boletins e periódicos acadêmicos, contratos de gestão, revistas e sites de Organizações Sociais sobre essa modalidade de mercantilização e finaliza refletindo os efeitos privatistas dessa lógica de gestão e como ela conjuga a legitimação e a acumulação do capital.

\section{A ORGANICIDADE ESTADO E CAPITALISMO EXPRESSA NA PRIVATIZAÇÃO DAS FUNÇÕES SOCIAIS ESTATAIS}

Em oposição à ciência e àpolítica burguesa que explica o Estado como ente apartado das relações sociais e, consequentemente, corrobora uma estrutura política ideologicamente funcional à naturalização do domínio do capital sobre o trabalho, a tradição marxista apreende o Estado como 
parte orgânica da totalidade capitalista e inserido na dinâmica das relações sociais de produção da sociedade burguesa. Ainda que Karl Marx não tenha elaborado uma teoria sistematizada do Estado, a dimensão de totalidade sobre a realidade social, intrínseco às investigações desse autor, fez com que odebate sobre Estado e políticafosse transversal em suas obras (NETTO, 1987). Nelas, contrapõe-se, criticamente às interpretações isoladas e equivocadas dos teóricos burgueses a respeito do papel do Estado e do poder político, demonstrando as contraditórias e intrínsecas relações entre as esferas política e econômica.

Essa interação de unidade dialética entre Estado e capitalismo é evidenciada, dentre outras formas, por meio da presença do Estado nas relações de produção e reprodução do capital. Concretamente, as relações de produção e a economia são compostos de elementos sociais e políticos, visto que se caracterizam "como relações de dominação, como direitos de propriedade, como o poder de organizar e governar a produção e a apropriação" (WOOD, 2011, p. 31-32). Dentre as determinações essenciais do Estado, também se encontra a polarização social entre classes sociais: dominante e dominada, e a necessidade, daí decorrente, de uma expressão do domínio político e social da classe dominante. Tais processos possuem uma inter-relação contraditória, suas ações e funções voltam-se para a reprodução das relações de dominação e legitimação social e política do sistema e, deste modo, incide direta e indiretamente, nos processos de acumulação, imprescindíveis ao capitalismo.

Logo, além da suaparticipação social e política, com vista à legitimação do sistema, 0 Estado está visceralmente inscrito no processo de produção, reprodução e acumulação. Isso quer dizer que o Estado assume diversas formas e funções que são indispensáveis ao desenvolvimento do capitalismo, tornando-se um importante elemento e instrumento da produção e reprodução deste. Eis porque este Estado se caracteriza como sendo de classe, conforme Poulantzas (1980), e, tal como o capital revela-se uma relação social orgânica ao capitalismo, o que evidencia que este não é um sistema estritamente econômico, mas também político e social.

Essa imbricação entre as esferas política e econômica é uma constante no processo de desenvolvimento histórico do capitalismo, mas se acentuou a partir do século XX. No contexto do póssegunda guerra, na monopolização do capital e das demandas de socialização dos custos produtivos deste estágio capitalista, atuando na reprodução econômica, pela via direta, o Estado tornou-se um grande fomentador do processo de acumulação da classe burguesa. Do mesmo modo, assumiu protagonismo também da reprodução social, correspondendo às lutas da classe trabalhadora e 0 consequente fortalecimento dos princípios democráticos e de cidadania burgueses, com isso, verificouse 0 amadurecimento e ampliação das suas funções e políticas sociais, o que afirmou o perfil de Estado Social. Assim, embora o Estado Social represente um avanço no campo das relações sociais 
capitalistas, ele não pode ser compreendido de forma dissociada das demais relações que compõem esse sistema, já que ele assumiu a reprodução ampliada da classe trabalhadora sem, com isso, mexer nas estruturas econômicas e na socialização de riquezas. (GOUGH, 1982; HARVEY, 2008).

As transformações no padrão de acumulação do capital, com a crise estrutural de 1970, a predominância do capital financeiro, mundialização e o neoconservadorismodesferiram severos ataques ao intervencionismo do Estado, mas, não se desfez dele, ao contrário, também o tornou funcional à reprodução ampliada do capital. Efetivamente, a nova etapa de acumulação do capital é marcada pela forte ação do Estado na garantia das condições de produção e nas práticas econômicas que envolvem a financeirização do capital. Dentre essas ações, encontram-se a forte atuação do Estado frente a um dos maiores sistemas de acumulação financeira atuais, a dívida pública, que ocorre totalmente afiançado pelo Estado. Nesse movimento, os avanços progressistas, as bandeiras de luta da classe trabalhadora, que estão na base do Estado social democrático, foram fortemente atacadas (HARVEY, 2005).

De tal modo, o Estado, sob essa direção e conotação, vem se desfazendo da sua feição social e afirmando, cada vez mais, uma postura de hostilidade em relação à satisfação pública de legítimas necessidades sociais. Por outro lado, as contradições sociais que decorrem deste padrão atual de acumulação capitalista acentuam as manifestações da questão social. Apesar do forte ataque ao Estado e a defesa do livre mercado, as consequências sociais do metabolismo irracional da acumulação capitalista têm exigido a adoção de uma rede de provisão social mínima, mas imprescindível à manutenção da coesão social necessária à legitimação do sistema.Este quadro social agravou-se com a pandemia de Covid-19 que expôs a fragilidade das políticas sociais e evidenciou a importância do Estado no campo da proteção social do capitalismo.

Contudo, no contexto atual, esta provisão social mínima tem sido viabilizada por meio de estratégias que privilegiam o mercado e setores empresariais, através de parcerias público-privadas, que a partir do financiamento público gerenciam serviços sociais de natureza pública, configurando o que denominamos de privatização de funções sociais do Estado, que tem se mostrado uma estratégia de viabilização dos mecanismos de acumulação e legitimação do capital.

Esse movimento vincula-se à tendência mundial de retorno dos serviços, funções sociais e ações ligadas ao bem-estar em mãos privadas, e tem, nos organismos internacionais, uns dos maiores interlocutores e promovedores destas estratégias e pautas da proteção social, as impondo aos países periféricos por meio dos ajustes estruturais. Essas agendas têm ampliado a ação mercantil em torno da política social em todos os âmbitos, ou seja, elas defendem que saúde e educação devem ser oferecidas pelo mercado e ofertadas pelos critérios desse. Para os que não podem comprar, defendem pautas de focalização do acesso com base em critérios e condicionalidades. Ainda, nesse caso, a 
provisão não deve ser exclusivamente pública, mas através de parcerias público-privadas, o que também amplia as possibilidades de exploração mercantil, por meio da proteção social pública.

As saídas da crise capitalista, portanto, abriram as fronteiras da expansão mercantil para 0 campo da proteção social. Tal movimento revela-se como nova dinâmica de expropriação do capital de setores antes não explorados pelo mercado, como políticas sociais, inserindo-as no seio da produção direta do capital, tornando-se importantes mercados a serem explorados e condicionadas às necessidades da acumulação do capital, ao mesmo tempo em que se garante a legitimação e o controle pelas classes e frações de classe dominadas a quem se destina, cumprindo o objetivo de obtenção de consenso e conformação ideológicos.

Essa modalidade de privatização, envolta em medidas de diminuição do papel do Estado na execução dos serviços sociais lucrativos, mas sem eximi-lo da provisão de suporte econômico, tem sido fortemente utilizada no campo da política de saúde. Almeida (2017) afirma que esses mecanismos foram compondo a agenda de ajustes do Banco Mundial e do Fundo Monetário Internacional e, por meio deles, abriu-se espaço "para o setor privado nas políticas públicas, com a supervalorização do mercado e da perspectiva empresarial, concomitantemente à desqualificação do Estado, das políticas sociais e da provisão de bens públicos (ALMEIDA, 2017, p. 03).

Em vista disso, a efetividade do Estado, como provedor de serviços, começou a ser questionada pelos formuladores de políticas das agências multilaterais que alegavam a importância de todos os agentes sociais no tratamento das demandas sociais, públicas ou privadas. Com isso, passou a predominar um processo de separação entre a provisão social e o financiamento desta, por meio de estratégias administrativas que têm transformado o Estado em um comprador de serviços prestados pelo setor privado, fortalecendo a capacidade estatal de regulação e dando-lhe a tônica de um Estado eminentemente regulador. Com esses artifícios, tem predominado a deslegitimação do interesse público, e a delegação das funções sociais do Estado para atores privados; e isso, na prática, significa fazer do espaço e do valor socialmente criado em favor do orçamento público, um meio de expansão lucrativa do capital.

\subsection{A privatização das funções sociais do estado brasileiro}

Para abordar a dinâmica da privatização das funções sociais do Estado brasileiro, é necessário demarcar as particularidades de formação sociopolítica deste país, marcadas pelo capitalismo dependente que, como um padrão de acumulação condicionado e subordinado a economias dominantes, exigiu forte protagonismo do Estadona criação das condições gerais para 
produção capitalista, bem como nos aspectos ligados à reprodução ampliada da classe trabalhadora, por meio de funções sociais e do controle das ameaças desta classe ao sistema (FERNANDES, 1975).

Tais características moldaram um perfil de Estado autocrático, decorrente da frágil construção democrática e alinhado às demandas lucrativas das classes dominantes (FERNANDES, 1975). Esses elementos imprimiram à proteção social brasileira um lastro privatizante desde sua gênese. De tal modo, a aceitação das medidas sociais e trabalhistas pelas elites dominantes, na ordem burguesa, partiu da sua percepção de ganhos econômicos advindos com esse processo, vinculados à ação controladora, repressiva e de cunho corporativo (GOMES, 1979).

Assim, as políticas sociais, como parte das funções sociais do Estado capitalista brasileiro, surgem atreladas às lutas da classe trabalhadora, mas também como importante meio de acúmulo do capital. Sob este ímpeto, estas políticas, para além de responderem às requisições por reprodução ampliada da força de trabalho e às necessidades sociais criadas pelas novas relações de produção, como a qualificação de mão de obra e segurança sanitária, assumem um perfil restrito e visceralmente vinculado às necessidades do capital. Dessa forma, a proteção social estruturou-se como "espaço de valorização do capital" (DRAIBE, 2004, p. 67).

No contexto de redemocratização, e sob forte pressão social, o desenho da proteção social e da política social brasileira se transformou. Rompeu-se, formalmente, com o modelo da cidadania regulada, segmentado e verticalizado, e incorporou-se ao modelo de Seguridade Social inspirada nos sistemas beveridgianos de países capitalistas centrais, como a Inglaterra, mostrando-se como a expressão mais progressista no campo dos direitos sociais (BOSCHETTI, 2009). Destas conquistas sociais, destaca-se o direito social à saúde, implementado mediante o SUS, contrapondo-se ao perfil coorporativo e segmentado da política pública de saúde brasileira vigente.

Entretanto, a Constituição Federal do Brasil de 1988 - CF/88 não conseguiu romper com as linhas privatizantes que associavam a política social à acumulação do capital, tornando-se alvo de intensos ataques e disputas entre projetos societários conflitantes, particularmente no contexto de hegemonia da política macroeconômica neoliberal, que vêmrestringindo e desconfigurando a implementação de medidas de proteção social e os direitos previstos na Constituição, ao não uniformizá-los e universalizá-los, enfraquecendo os seus espaços de participação e controle social, ao mesmo tempo em que fizeram deste novo e progressista sistema de proteção social uma nova via de expansão mercantil, marcando uma etapa em que a função social pública do Estado passou a ser mercantilizada.

Um dos marcos desse processo de reestruturação foi a contrarreforma do Estado de 1996 (BEHRING, 2003), institucionalizada no primeiro governo Fernando Henrique Cardoso - FHC, que, fundamentada em um forte ataque ao Estado, promoveu a suareorganização administrativa eformalizou 
meios de exploração mercantil das funções sociais do Estado, bem como estruturou mecanismos que adequavam o Estado brasileiro às demandas da nova etapa de acumulação do capital com base no mercado financeiro,como a dívida pública. Assim, essa contrarreforma, ao invés de diminuir o papel do Estado frente ao mercado, o colocava como próprio meio de acumulação.

A reforma administrativaredefiniu o papel do Estado no campo da intervenção social, retirando sua responsabilidade direta com a execução de políticas sociais, formalizadas na CF/88. Esta reestruturação se deu por meio da criação de segmentos específicos do Estado: setores estratégicos e exclusivos, retirando a responsabilidade estatal com serviços e funções sociais, particularmente as políticas sociais de saúde e de educação, os transformando em serviços não exclusivos. No rastro desta segmentação classificatória das atividades do Estado em exclusivas e não exclusivas, o Plano Diretor da Reforma do Estado - PDRE implementou novas formas de propriedade pública: propriedade estatal, que agrega os setores exclusivos do Estado, e propriedade pública não-estatal, que engloba os serviços não exclusivos do Estado (PDRE, 1995, p. 43).

A reforma da administração pública brasileira foi efetivamente institucionalizada pela Emenda Constitucional $n^{0}$ 19/1998 e pelo Programa de Publicização previsto no Plano Diretor e criado com a Lei n 9.637, de 15 de maio de 1998, que também criou as Organizações Sociais - OS, uma das primeiras modalidades de pessoa jurídica de direito privado abrangidas pelo conceito de público nãoestatal. Na esteira dessa legislação, foi criada também a Organização da Sociedade Civil de Interesse Público (OSCIP), pela Lei n 9.790, de 23 de março de 1999, que também se define como privada sem fins lucrativos, voltada para atividades de interesse social e/ou de utilidade pública não exclusivas do Estado. Estas inovações no campo da gestão foram implementadas na política de saúde, desencadeando a contrarreforma na saúde (CORREIA, 2007), que também teve suas bases em documentos elaborados pelo Banco Mundial.

Nos governos petistas, essa dinâmica de terceirização da gestão de políticas sociais se manteve, mas com algumas modificações, entre as quais consta a criação de entidades vinculadas à administração pública, porém regidas pelo direito privado, descontadas algumas diferenças em seus estatutos. Neste processo, se destaca a criação da Empresa Brasileira de Serviços Hospitalares (EBSERH), vinculada ao Ministério da Educação, mas que se enquadra na administração pública indireta como empresa pública unipessoal e de personalidade jurídica de direito privado, pavimentando uma "via de privatização do maior sistema hospitalar público brasileiro - os 47 hospitais universitários" (CORREIA; SANTOS, 2015, p. 36).

Com base nestes estatutos legais, o estado do Maranhão, em 2015, criou a Empresa Maranhense de Serviços Hospitalares - EMSERH, que tem natureza de empresa pública, mas regida por personalidade jurídica de direito privado e que visa gerenciar a rede pública de saúde maranhense. 
No Distrito Federal, em 2017, foi criado o Instituto Hospital de Base do Distrito Federal - IHBDF, Serviço Social autônomo de pessoa jurídica de direito privado sem fins lucrativos, terceirizando a gestão do maior hospital do DF. Em 2019, por meio da Lei $n^{0}$ 6.270, o nome do IHBDF foi alterado para Instituto de Gestão Estratégica de Saúde do Distrito Federal - IGESDF, ampliando seu limite de atuação assistencial às unidades de pronto atendimento - UPAs e ao Hospital Regional de Santa Maria.

Tais medidas administrativas de flancos mercantis se fortaleceram com o golpe parlamentar de 2016 e com o governo Temer, que promoveu um intenso ataque ao SUS e às demais políticas sociais brasileiras, com a contenção dos gastos sociais públicos pela Emenda Constitucional 95/2016. Tais ações contam também com o apoio do Banco Mundial que, por meio do documento "propostas de reformas do sistema único brasileiro", de 2018, propõe aprofundar e universalizar esta estratégia privatista, já que, segundo o documento, "há fortes evidências de que os hospitais que funcionam com gestão autônoma, tais como a das Organizações Sociais em Saúde (OSS) têm melhor desempenho do que os que estão sob administração pública direta" (BANCO MUNDIAL, 2018, p. 12).

No governo de extrema direita de Jair Bolsonaro, a agenda neoliberal ortodoxa, abertamente privatista e a favor do mercado, vem fortalecendo esses processos de privatização das funções sociais do Estado. Este cenário privatista acentuou-se com a crise sanitária provocada pela pandemia de covid-19, já que em meio às atitudes de negação das evidências cientificas e o desprezo das medidas de controle sanitário por parte do presidente, houve o fortalecimento dessas modalidades de gestão, conforme veremos a seguir.

\subsection{A privatização das funções sociais do Estado via terceirização da gestão da saúde}

Com base nessa arena política, e no desenho administrativo da contrarreforma do Estado da década de 1990, tem predominado no Brasil a opção por esse modelo de gestão, especialmente as Organizações Sociais. Segundo dados do IBGE, colhidos pela pesquisa ESTADIC de 2018, a maioria dos estados de todas as regiões do Brasil têm instituições públicas gerenciadas por essas modalidades ou por instituições com natureza jurídica semelhante. Na região Norte: o estado do Acre tem 01 instituição gerenciada por OSCIP; o Amapá tem 02, enquanto o Pará tem 14 instituições gerenciadas por OS. Esta modalidade de gestão também predomina na região Nordeste, sendo: Bahia: 28; Ceará: 01; Maranhão: 12; Paraíba: 09; Pernambuco: 36; Piauí: 01(IBGE, 2018).

No Centro-Oeste, o estado de Goiás tem 17 instituições nesta modalidade; Distrito Federal tem 01 instituição vinculada a OSS e dois hospitais gerenciados pelo IGES, entre eles o maior hospital de Brasília, o Hospital de Base; Mato Grosso 02 e Mato Grosso do Sul 02 instituições gerenciadas por OS. A Região Sudeste concentra a maioria de instituições gerenciadas por essas modalidades de 
gestão, com destaque para o estado de São Paulo, que possui 83 instituições; Rio de Janeiro: 42 e 0 Espírito Santo: 24, sendo 04 OSS e 18 OSCIP (IBGE, 2018). Na Região Sul, segundo os dados do IBGE (2018), apenas Santa Catarina tem 03 hospitais sob gestão de OSS. Contudo, em municípios do estado do Paraná e Rio Grande do Sul existem instituições de saúde gerenciadas por OSS. O mesmo acontece com o Estado de Minas Gerais e Ceará, dentre outros. Tais dados não foram computados aqui em razão dos objetivos do texto, que buscam mapear as gestões de instituições estaduais de saúde.

No contexto da crise sanitária desencadeada pela pandemia da covid-19, as medidas de assistência à saúde desempenhadas pelos governos estaduais, como os hospitais de campanha, privilegiaram esta modalidade de gestão, garantindo que em meio a esta histórica tragédia social, esses segmentos mercantis fossem favorecidos. Isto porque, os hospitais de campanha montados nos principais estados das cinco regiões brasileiras ficaram a cargo da gestão de OSS, a exemplo de São Paulo, Pará, Goiás, Rio Grande do Norte, Mato Grosso do Sul e Santa Catarina, dentre outros. O mesmo ocorreu no Distrito Federal, a partir de parcerias por meio de cooperação técnica entre a secretaria de saúde do DF e o IGES- DF, conforme informações colhidas em sites jornalísticos.

Importa situar que parte das OSS, responsáveis pela gestão dos hospitais de campanha, esteve envolvida em práticas de corrupção, com destaque para o estado do Rio de Janeiro, cujos escândalos de desvios de recursos públicos levaram ao impeachment do Governador Wilson Witzel.

Nesse movimento, em que a própria função pública se mercadoriza, predomina a diminuição das ações do Estado em razão do setor privado. Este artifício alavancado e estimulado pelo próprio Estado embasa-se em variados constructos ideológicos, entre os quais se encontra a concepção de "público não-estatal" que busca reforçar o "terceiro setor" com espaço privilegiado de produção de bem-estar, uma vez que pode conjugar medidas públicas com contribuições do mercado e, principalmente, forças sociais solidárias na sociedade civil. Por conseguinte, consideradas as relações de totalidade entre o Estado e o sistema capitalista, a divisão entre primeiro, segundo e terceiro setor esconde o Estado como um partícipe primordial da acumulação e da legitimação do sistema em vigência, escondendo a dimensão de totalidade e de organicidade entre política e economia sobre a qual se assenta a dominação burguesa.

Além do mais, cria-se um véu ideológico que encobre os elos entre essas dimensões, como o caráter não governamental dessas entidades que, ao contrário do que divulgam, não possuem um perfil autogovernável, já que elas imprescindem do financiamento público para funcionar. Sobre isso, o boletim especial "Organizações Sociais na saúde", do Instituto Alta Complexidade Política e Saúde, com bases em investigações realizadas pela Polícia Federal, aponta que "as Organizações Sociais no Brasil não demonstram outra fonte de renda que não sejam, exclusivamente os recursos 
públicos" (2017, p. 31). Deste modo, verifica-se a falácia do caráter não lucrativo dessas entidades que só exercem suas ações mediante várias modalidades de fomento econômico, oferecidas pelo Estado.

Salienta-se também que essas entidades, mesmo tendo respaldo jurídico, que Ihes preserva de questionamentos lucrativos, e suas ações se voltem para o interesse social, elas possuem personalidade jurídica privada e, portanto, atuam sob critérios da lucratividade em contraposição ao público e coletivo.As evidências do caráter lucrativo dessas entidades mostram-se pelo crescente número de instituições criadas sob esta modalidade jurídica de OSS, a ponto de se organizarem em uma Associação Nacional representativa das Organizações Sociais, denominada de Instituto Brasileiro das Organizações Sociais de Saúde (IBROSS), criada em 2015 e que conta com 21 associadosque atuam em vários estados e que gerenciam, juntos, mais de 800 unidades de saúde (IBROSS, 2020).

Entre os associados, encontra-se o Instituto de Responsabilidade Social Sírio Libanês e a Albert Einstein Sociedade Beneficente Israelita Brasileira, gigantes do setor privado em saúde, mas com natureza jurídica de OS, ou seja, entidades sem finalidade lucrativa que estão, respectivamente,nas posições 310 e 236no ranking das maiores empresas do Brasil no segmento de serviços médicos do Jornal Valor Econômico, do ano de 2018.Além destas, outras Organizações Sociais do IBROSS também estão neste ranking, a saber: a Associação Congregação de Santa Catarina, que gerencia 15 estabelecimentos de saúde, na posição 315; o Hospital Santa Marcelina, que gerencia 07 hospitais públicos e privados, na posição 408; a Associação Paulista para 0 Desenvolvimento da Medicina - SPDM, que aparece no ranking com o nome de sua matriz - o Hospital São Paulo -ocupa a posição 112 no ranking geral e o segundo lugar entre as maiores do setor (VALOR ECONÔMICO, 2019). Além do hospital São Paulo, a SPDM administra mais 18 instituições de saúde, além de outros estabelecimentos de saúde, como ambulatórios, centros e farmácias de alto custo. № contexto da pandemia de covid-19 também administrou 04 hospitais de campanha, segundo informações colhidas em seu site.

Fora da IBROSS, encontram-se, ainda, neste ranking econômico, duas importantes OS no campo da saúde: a Associação Beneficente de Assistência Social e Hospitalar - Pró-Saúde, na posição 484, atuando em todas as regiões do país na gestão de28 estabelecimentos de saúde, entre hospitais de gestão estadual, municipal e privados; e a Fundação do $A B C$, que é responsável pela gestão de 19 instituições e ocupou a colocação 282 no ranking geral, ficando em $8^{\circ}$ lugar entre as 10 maiores do setor (VALOR ECONÔMICO, 2019).

Ademais, torna-se questionável o caráter não lucrativo dessas entidades quando se analisa a própria descrição mercadológica destas em seus próprios sites, como 0 da Pró-Saúde, que fomenta a participação de setores no investimento do que eles denominam "mercado de saúde", que tem se mostrado "um dos mercados mais promissores para investimentos nos próximos anos", já que o 
gerenciamento de "unidades hospitalares recém-adquiridas" torna-se "um grande atrativo aos grandes fundos de investimentos nacionais e internacionais" (PRO-SAÚDE, 2020).

A vinculação dessas entidades com o mercado financeiro é exposta também em seus contratos de gestão, a exemplo do contrato firmado entre a pró-saúde e a Secretaria de Saúde do estado do Pará, na clausula $5^{\mathrm{a}}$, que trata dos recursos financeiros e da dotação orçamentária, no item 5.2 ,onde prevê que "os recursos repassados à Contratada poderão ser aplicados no mercado financeiro, desde que os resultados dessa aplicação revertam-se, exclusivamente, aos objetivos desse contrato"(CONTRATO DE GESTÃO/SESPA-PRÓ-SAÚDE, 2017). Este movimento de privatização, portanto, está atrelando, sob novas formas de usurpação, o fundo público à dinâmica da financeirização do capital, movimento que já ocorre com o sistema da dívida pública.

Cabe questionar também 0 argumento de racionalização dos gastos e desburocratizaçãocom a saúde por meio dessas modalidades de gestão, já que, segundo dados do boletim "organizações sociais na saúde", este argumento se desconstrói quando se detalha as informações financeiras das entidades e dos contratos, visto que "ficam constatadas como serviços abusivamente mais caros", havendo uma discrepância entre os valores dos serviços de saúde das secretarias de saúde e os desenvolvidos pelas OSS, a exemplo da comparação entre os financiamentos da gestão indireta por meio das organizações sociais e a gestão direta pelo SUS no Estado da Paraíba, conforme dados do mesmo boletim: a Maternidade Passos de gestão indireta por OSS, com 94 leitos teve pago o valor deR\$32.153.653,45; já o Hospital Regional Patos de gestão direta pelo SUS, com 115 leitos teve valor pago de $\mathrm{R} \$ 8.272 .332,70$. Ambas estavam voltadas para a mesma população de 107.067 habitantes, segundo dados do IBGE de 2016 (POLÍTICA E SAÚDE, 2017, p.2).

Embora essas modalidades de gestão da política pública de saúde sejam justificadas como práticas administrativas de racionalização orçamentária, e de harmonização entre as esferas pública e privada por meio do denominado terceiro setor, concretamente elas promovem uma readequação dos aparelhos do Estado às demandas do mercado no campo das políticas sociais. Revela-se, desse modo, como um importante instrumento para alavancar um processo de privatização velado que, por meio de políticas sociais, garante financiamento público para entidades isentas das regras do controle público. Além disso, reforça uma justificação ideológica de sincretismo entre público e privado, em que as atividades públicas podem e devem ser desenvolvidas por particulares e/ou de iniciativas particulares com sentido público, como se esse sincretismo fosse isento de interesses econômicos.

Pondera-se também que esse processo de privatização, nos moldes de transferência de gestão e de execução de funções sociais do Estado, é uma inovação dessa conjuntura atual brasileira 
e corresponde às tendências mundiais no campo da proteção associada ao mercado, visto que, antes da CF/88, a provisão de políticas sociais por meio de parcerias público-privadas ocorria primordialmente sob a modalidade de compra dos serviços de instituições privadas, da qual a política de saúde foi exemplar. Assim, considera-se que esta ação é parte de uma estratégia ampla de recomposição das taxas de acumulação do capital por meio da apropriação do fundo público que sustenta e garante estas funções sociais do Estado, haja vista que só recentemente assiste-se, com regularidade, a iniciativa privada (com ou sem fins lucrativos) ofertar serviços sociais à sociedade segundo o princípio público.

Ainda que seja uma inovação, este processo retoma e recompõe, por meio de uma formalização legal, antigas práticas de interação público-privada no campo da política pública de saúde, já que dadosadquiridos por uma auditoria realizada pelo Tribunal de Contas da União (TCU) em Organizações Sociais que executam serviços ligados à política de saúde apontaram a inexistência de "estudos de critérios técnicos e objetivos que comprovassem que a gestão terceirizada traria melhores resultados", assim como a ausência de controle social sobre essas entidades (TCU, 2016, p. 04).

A articulação de interesses públicos e privados, nesse campo, faz com que a política de saúdese converta em importante meio de acumulação para segmentos privados de saúde. Estes têm se utilizado dessas mudanças da administração pública brasileira para adquirir natureza jurídica de entidades públicas não estatais, camuflando seus interesses mercantis em torno dos recursos públicos que asseguram a política pública de saúde.

Esse processo, ao ser priorizado, conduzido e respaldado pelas instâncias governamentais do Estado brasileiro, evidencia o seu papel estratégico na mediaçãodas relações sociais do capitalismo, assegurando com a oferta pública da assistência à saúderespostas às lutas sociais pelos direitos sociaise a legitimidade social, ao mesmo tempo que articula essas ações com os interesses mercantis e acumulativos de grupos empresariais que lucram mediante a execução dessa política.

Essas práticas, contudo, além de fomentar a exploração lucrativa de recursos públicos, favoreceram práticas corruptas como "contratos de gestão que estabelecem a remuneração de $100 \%$ do valor, mesmo quando cumpridos apenas $80 \%$ dos serviços contratados", conforme dados obtidos pelo boletim política e saúde, que também apontam outras irregularidades como descumprimento de metas, atraso na folha de pagamentos com pessoal, o não recolhimento das contribuições sociais, a sede da entidade fora da região de atuação, a falta de comprovação de experiência da instituição, evidenciando que várias entidades foram criadas apenas com a finalidade da prestação de serviços (POLÍTICA E SAÚDE, 2017, p.26). Além desses fatores, investigações da Polícia Federal, mostradas neste boletim, identificaram também fragilidades e irregularidades referentes ao controle e fiscalização 
dos recursos públicos administrados por essas entidades, comouso de conta corrente privada, "permitindo saques de milhões em recursos repassados às Organizações Sociais [...] contratações não são públicas [...] obscuras, não estão no Diário Oficial” (POLÍTICA E SAÚDE, 2017, p.30).

Ademais, estas entidades realizam "controle deficiente da carga horário dos médicos; médicos contratados via terceirização que fazem parte do quadro de pessoal do município ou de municípios vizinhos" (TCU, 2016, p. 6). Cabe ressaltar também que essas modalidades de gestão precarizam e flexibilizam as relações de trabalho, implicando perda de direitos trabalhistas e previdenciários, além de enfraquecer a organização das categorias profissionais e de suas lutas, consequentemente.

Dessa forma, em vez de publicização das funções sociais do Estado, tem-se um movimento de despublicização, isto é: um processo que retira dessas funções o seu princípio público e as insere em uma estrutura organizacional permeável a maior participação dos agentes privados, o que tem resultado na sua captura pela dinâmica mercantil, promovendo a sua privatização e demonstrando que esse modelo de gestão repousa "sobre um conjunto de componentes ético-políticos que não expressam as finalidades vinculadas a uma dimensão pública de universalização de direitos" (SOUZA FILHO, 2006, p. 304).

Esses acontecimentos revelam a existência do viés mercadológico em torno das funções sociais públicas e afirma a premissa de que a política social, parte destas funções do Estado, vem servindo como instrumento pelo qual o capital se apropria do fundo público, ao mesmo tempo em que se configura uma contraditória estratégia de legitimação e dominação do capital sobre as classes subalternas, medidas implementadas e conduzidas pelo próprio Estado, o que evidencia sua natureza de classe e de organicidade com o capitalismo.

\section{CONSIDERAÇÕES FINAIS}

A intenção deste artigo foi de demonstrar que a terceirização da gestão de serviços públicos de saúde se consubstancia como privatização das funções sociais do Estado capitalista, desencadeando uma dinâmica mercantil em tarefas próprias e internas ao Estado e produzindo a privatização mercantilizada do que, em princípio, seria público, com a colaboração do próprio Estado. Esta engenharia conjuga, com base em outras determinações, a histórica relação entre acumulação e legitimação, tendo como elo central as funções sociais do Estado capitalista, especialmente na conjuntura de sua crise estrutural.

Também resulta da necessidade irrefreável do capitalismo de renovar constantemente 0 seu processo de produção de mercadoria e de acumulação de riqueza, valendo-se, não apenas da 
economia, mas também de condições sociais e políticas criadas pelo Estado. Embora essemovimento tenha respaldo legal, não está dissociado de uma lógica mercantil que aloca serviços sociais às necessidades expansivas de lucro do capital. Este respaldo jurídico camufla e legitimaum processo de extração de riqueza social para o capital e transforma os interesses das classes dominantes em um ilusório interesse comum.

\section{REFERÊNCIAS}

ALMEIDA, C. Parcerias público-privadas no setor saúde: processos globais e dinâmicas nacionais.

Cadernos de Saúde Pública, v. 33, p. 1-16, 2017.

ASSOCIAÇÃO BENEFICENTE DE ASSISTÊNCIA SOCIAL E HOSPITALAR - PRÓ-SAÚDE. Por que investir no mercado de saúde do Brasil? Disponível em: https://www.prosaude.org.br/. Acesso em: 10 jul. 2020.

BANCO MUNDIAL. Propostas de Reformas do Sistema Único de Saúde Brasileiro. [S. I.]: BIRD AID. 2018.

BEHRING, E. R.Brasil em contra-reforma: desestruturação do Estado e perda de direito. São Paulo, Cortez, 2003.

BOSCHETTI, I. A Política de Seguridade Social no Brasil. In: Serviço Social: Direitos Sociais e Competências Profissionais. 1. ed. Brasília: CFESS, 2009.

BRASIL. Plano Diretor da Reforma do Aparelho do Estado. [S. I.]: [s. n.], 1995.

CORREIA, M. V. C. A saúde no contexto da crise contemporânea do capital: o Banco Mundial e as tendências da contrarreforma na política de saúde brasileira. In: Temporalis, Política de Saúde e Serviço Social: impasses e desafios. São Luiz: ABEPSS, 2007.

DRAIBE, S. Rumos e metamorfoses: Um estudo sobre a constituição do estado e as alternativas da industrialização no Brasil, 1930-1960. 2. ed. Rio de Janeiro: Paz e Terra, 2004.

FERNANDES, F. Capitalismo Dependente e as Classes Sociais na América Latina. 2. ed. Rio de janeiro: Zahar, 1975.

GOMES, A. C. Burguesia e Trabalho: política e legislação social no Brasil 1917-1937. Rio de Janeiro: Campus, 1979.

GOUGH, I. Economia política del Estado delbienestar. Madri: H. BlumeEdiciones, 1982.

HARVEY, David. Condição pós-moderna: uma pesquisa sobre as origens da mudança cultural. 17. ed. São Paulo: Loyola, 2008.

HARVEY, D. O Neoliberalismo: história e implicações. Edições Loyola. 2005. 
INSTITUTO ALTA COMPLEXIDADE POLÍTICA E SAÚDE. Especial Organizações Sociais na saúde. 6. ed. ano 3, Brasília: [s. n.], 2017.

INSTITUTO BRASILEIRO DAS ORGANIZAÇÕES SOCIAIS DE SAÚDE - IBROSS. Disponível em:https://www.ibross.org.br. Acesso em: 14 de jul. 2020.

INSTITUTO BRASILEIRO DE GEOGRAFIA E ESTATÍSTICA - IBGE. ESTADIC - Perfil dos Estados brasileiros. 2018. Disponível em: https://cidades.ibge.gov.br/brasil/. Acesso em: 15 jul.2020.

NASCIMENTO JUNIOR. Apesar da Covid-19 Organizações Sociais da Saúde (OSS) crescem por todo o Brasil. In: Boletim CEBES, [S. I.]: [s. n.], 2020. Disponível em: http://cebes.org.br. Acesso em: 30 set. 2020.

NETTO, J.P. Lenin e a instrumentalidade do Estado. Expressão Popular. São Paulo: [s. n.], 2010.

POULANTZAS, N. O Estado, o poder, o socialismo. Edições Graal. Rio de Janeiro: [s. n.], 1980.

SECRETARIA DE ESTADO DE SAÚDE PÚBLICA DO ESTADO DO PARÁ- SESPA. Contrato de gestão n004/SESPA/2017. Diário Oficial do Estado do Pará nº 33516, p. 36. Belém: DOU, 2017.

SOUZA FILHO, R.Estado, burocracia e patrimonialismo no desenvolvimento da administração pública brasileira. Rio de Janeiro: [s. n.], 2006.

TRIBUNAL DE CONTAS DA UNIÃO. ACÓRDÃO № 2057/2016 - TCU. [S. I.]: [s. n.], 2016. Disponível em: https://www.lexml.gov.br/urn/urn:lex:br:tribunal.contas.uniao;plenario:acordao:2016-08-10;2057. Acesso em: 27 set. 2018.

VALOR ECONÔMICO. [S. I.]: [s. n.], 2019. Disponível em: www.valor.com.br. Acesso em: 17 jul. 2020. WOOD, E. M. Democracia contra capitalismo: a renovação do materialismo histórico. São Paulo: Boitempo, 2011. 